\title{
Diffuse intracranial calcifications in a patient with untreated postoperative hypoparathyroidism
}

\author{
Orly Bogler MD, Steven L. Shumak MD
}

- Cite as: CMAJ 2021 December 13;193:E1890. doi: 10.1503/cmaj.210940

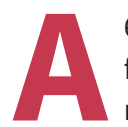

68-year-old woman presented to hospital after a fall. She had undergone a total thyroidectomy more than 20 years previously. Her neurologic examination was normal. Computed tomography scans of her head, done to exclude intracranial bleed, showed symmetric parenchymal calcification in the basal ganglia (Figure 1A) and cerebellum (Figure 1B).

Given the patient's history of thyroidectomy, we suspected hypoparathyroidism and arranged a series of laboratory tests. These showed an ionized calcium level of 0.75 (normal 1.15-1.35) $\mathrm{mmol} / \mathrm{L}$, and a phosphate level of 1.51 (normal $0.87-1.52$ ) mmol/L. Her parathyroid hormone level was undetectable at less than 0.6 (normal 1.4-7.6) $\mathrm{pmol} / \mathrm{L}$ and her thyroid-stimulating hormone level was 0.38 (normal 0.5-5.0) $\mathrm{mIU} / \mathrm{L}$. The presumptive diagnosis for the intracranial calcifications was chronic hypocalcemia caused by untreated hypoparathyroidism after total thyroidectomy.

Patients with total thyroidectomy remain at lifelong risk for hypoparathyroidism, even with apparently intact parathyroid glands in the postoperative period. Hypoparathyroidism typically presents with symptomatic hypocalcemia, manifesting as paresthesias, muscle spasms, tetany and seizures. However, as with our patient, chronic hypocalcemia can remain subclinical. An incidental finding of brain calcifications in patients with total thyroidectomy should prompt investigation for hypoparathyroidism, including measurement of serum calcium, phosphorus and parathyroid hormone.

The most common causes of basal ganglia calcification are hypoparathyroidism and pseudohypoparathyroidism. ${ }^{1}$ Other causes include metabolic and infectious entities, Fahr disease, and trisomy $21{ }^{2}$ The proposed pathogenic mechanism of basal ganglia calcification in hypoparathyroidism is an abnormal calcium-to-phosphorus ratio, leading to microscopic colloid deposition and perivascular calcification, most commonly in the basal ganglia. ${ }^{3}$ Extrapyramidal signs, cognitive dysfunction and seizures can develop, but were not present in our patient. ${ }^{2}$ Basal ganglia calcification is progressive; early and strict control of calcium and phosphorus is critical in preventing worsening disease. ${ }^{3}$

Treatment of basal ganglia calcification requires addressing the underlying cause; for patients with hypoparathyroidism, this includes treatment with calcium, vitamin $\mathrm{D}$ and possibly synthetic parathyroid hormone.
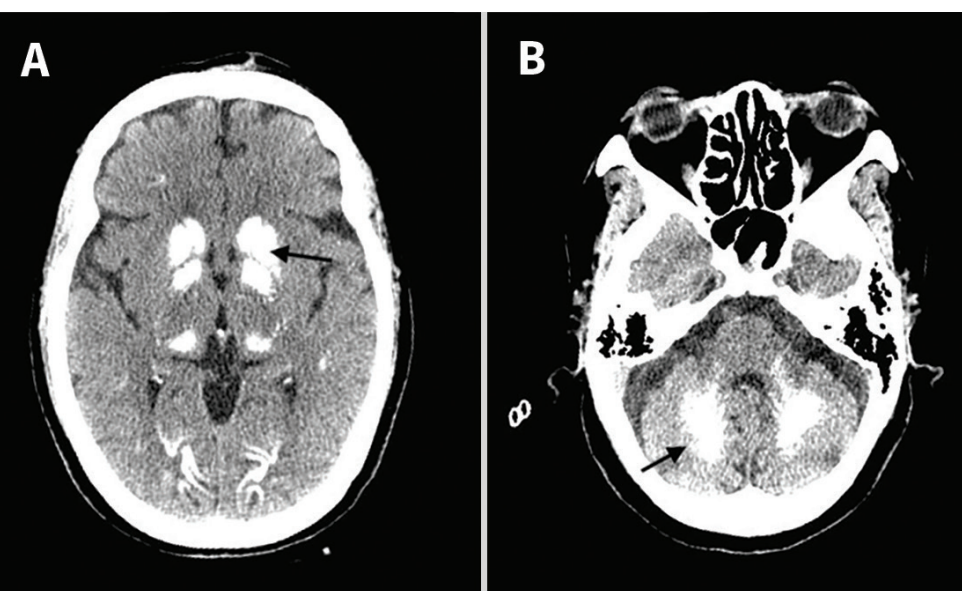

Figure 1: Computed tomography scans of the brain of a 68-year-old woman with hypoparathyroidism. Arrows show calcifications in both (A) the basal ganglia and B) the cerebellum.

\section{References}

1. Lorente-Poch L, Rifà-Terricabras S, Sancho JJ, et al. Prevalence of basal ganglia and carotid artery calcifications in patients with permanent hypoparathyroidism after total thyroidectomy. Endocr Connect 2020;9:955-62.

2. Saleem S, Aslam HM, Anwar M, et al. Fahr's syndrome: literature review of current evidence. Orphanet J Rare Dis 2013;8:156.

3. Goswami R, Sharma R, Sreenivas V, et al. Prevalence and progression of basal ganglia calcification and its pathogenic mechanism in patients with idiopathic hypoparathyroidism. Clin Endocrinol (Oxf) 2012;77:200-6.

\section{Competing interests: None declared.}

This article has been peer reviewed.

The authors have obtained patient consent.

Affiliation: Department of Medicine, University of Toronto, Toronto, Ont.

Content licence: This is an Open Access article distributed in accordance with the terms of the Creative Commons Attribution (CC BYNC-ND 4.0) licence, which permits use, distribution and reproduction in any medium, provided that the original publication is properly cited, the use is noncommercial (i.e., research or educational use), and no modifications or adaptations are made. See: https://creativecommons.org/licenses/by-nc-nd/4.0/

Correspondence to: Orly Bogler, orly.bogler@mail.utoronto.ca 